\title{
Rinti Wama
}

\section{Erhard Taverna}

Dr. med., Mitglied der Redaktion

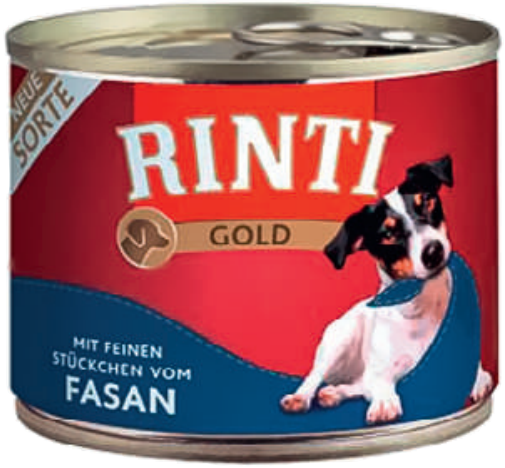

Drei Leidenschaften bestimmen mein Leben: Kochen, Marketing und Fifi. Drei unverzichtbare Säulen meiner, in aller Bescheidenheit gesagt, erfolgreichen Karriere als Werbechef eines Grosskonzerns. Ein Manager in meiner Position ist selten für sich alleine, ausser am Silvester. Das hat bei mir Tradition. Ist der Jetlag einmal ausgeschlafen, feiere ich das Jahresende mit Fifi in unserer Loft, nur wir zwei mit unseren Geschenken. Die ordinäre Knallerei mögen wir beide nicht. Lärm, Gestank und Verschwendung sind nicht mein Ding. Dieses Jahr gab es ein Auspackpaket mit GourmetHäppchen. Einmal die Hülle genussvoll zerrissen, kam die Überraschung an den Tag. Ein Spiel für den Profi. Schubfächer mit nichts als Schlaufen und Stempeln zum Öffnen, ein Intelligenztest, den mein Kamerad mit Bravour bestanden hat. Die Praline Dilli Dog hatte er sich reichlich verdient. Er mag Spielzeug. Etwa den Trixiegeier aus Plüsch, Marke Gustav, vom Vorjahr oder den weicheren Knuddelelch. Er stupft und knufft mich jeden Abend, bis wir die Kerle gemeinsam unter meiner Bettdecke suchen. Nur einmal haben wir auswärts gefeiert, in «Omas Küche» mit ihrem Spezialdinner für vierbeinige Begleiter. Danach gab es ein Foto mit Lätzchen fürs Album. Läppisch, ich koche uns lieber selber. Wenn die ersten Raketen und Heuler abzischen, was jedes Jahr früher geschieht, flüchten wir uns in die Kunst. Für mich gibt es Klassik und für Fifi die Anti-Angst-CD Don't be afraid, die Gold-Version mit mehr Tracks und längeren Spielzeiten. Ein Thundershirt gegen Stress mag er nicht, und Körperarbeit wie Tellington Touch gehört zu unserem täglichen Ritual. Ich verwöhnte ihn mit Pure Instinct Tundra Willow, Rentier pur, was ich nach Weihnachten sehr passend fand. Zum Nachtisch gab es Lachscreme und nach dem erzwungenen kurzen Gassigehen einige Straussencracker.

Wenn in unserer Firma jemand befördert wird, schickt der Aufsichtsrat eine Kiste Wein. Dem Kader schuldet dieser Jemand ein Essen, das stets in einem Lokal mit Gault Millaut weiss nicht wie vielen Punkten zelebriert wird. Jetzt bin schon wieder ich an der Reihe. Mein Vorsatz ist kühn und einmalig, denn nächste Woche habe ich alle zu mir eingeladen. Platz ist mehr als genug, der Salontisch ist riesig und die Küche ein perfekter, chromblitzender Ort der Inspiration. Wäre ich nicht schon Werbechef, würde ich Produkte entwickeln oder als Foodscout um die Erde reisen. Letzteres ist mein heimliches Hobby, vor allem wenn ich in Afrika oder Fernost unterwegs bin. Mein Beruf bringt mich auch mit Spezialisten des World-Food-Programms zusammen. Die machen interessante Sachen für Kinder, etwa Wama Mum in Pakistan aus angereicherten Kichererbsen oder Plumpy'Nut in Senegal, eine Erdnusspaste mit Nutellageschmack und Vitaminzusätzen. Aus technischer Sicht gibt es zahlreiche Parallelen zu unserem Konzern, es sind die gleichen Leute, die neue Sachen ausdenken. Nur dass unser Angebot viel grösser ist und die Produkte teurer, einmal weil nur Liebhaber dafür bezahlen und zum anderen die Vereinten Nationen unser Potential noch nicht entdeckt haben. Ich habe lange vorgekocht und ausprobiert, den Geschmack leicht verändert, Glutamat, Vanillin und Farbstoffe wie Carotin zugefügt. Menschen essen mit den Augen und nicht mit Fifis Nase. Zum Apéro gab es Rothirschsnacks und italienischen Schinkenknochen. Mein erster Gang, ein Gratin aus Soft Premium Känguruh mit zartem Wildgeschmack und leicht verdaulichen Pastinaken war schnell vertilgt, so dass ich für die nachfolgende Rinti-Gänse-ApfelMischung noch heimlich zusätzliche Büchsen öffnete. Die Schlemmerei begoss der Wein vom Aufsichtsrat Alle bestaunten meinen Fifi, der sich so benahm, als würde er alles kennen, was da auf den Tisch kam. Ein knusprig gebratener Marmor-Gugelhupf, bei dem ich die Geflügelleberwurst durch Hundeschokolade ersetzte, krönte den Speiseplan.

Die Tischdekoration, Windlichter aus perforierten Fettnapf-Büchsen mit Weihnachtskerzen, wurde als originelle Zugabe gelobt und festigte meinen Ruf als exzentrisches Original. Die sorgfältig abgelösten Etiketten gehören ab heute zu meiner Rezeptsammlung. Das wird mein nächstes Projekt sein. Ein weites Feld innovativer Zusammenarbeit und internationalem Austausch von kreativem Knowhow. Das Sortiment für unsere Lieblinge wird die Menschheit retten, denn Fifi sei Dank wird mein Konzern den Welthunger besiegen.

Und sollten alle Stricke reissen, was nicht geschehen wird. Dann tritt Plan B in Kraft. Wer, gemäss neuer Lebensmittelverordnung, ab diesem Jahr Insekten verspeist, wird bald auch Fifis konsumieren. Ausser meinen natürlich. 2016 beginnt das chinesische Jahr des Affen. Ich hätte für unsere Leserinnen und Leser auch dazu ein Rezept. 